\title{
Impact of Anxiety on Temporomandibular Joint Disorder in Some High School Students
}

\author{
Mi Suk Cho ${ }^{1}$, Nam Suk $\mathrm{Heo}^{2}$, Sang-hwan $\mathrm{Oh}^{3}$, Chang Suk Kim ${ }^{4}$, Man Hyu \\ $\mathrm{Huh}^{5}$, Sae Hee Cheon \\ ${ }^{I}$ Assistant Professor, Department Of Dental Hygiene, Choonhae College Of Health Sciences, Republic Of Korea \\ ${ }^{2}$ Professor, Department Of Dental Hygiene, Masan University, Republic Of Korea \\ ${ }^{3}$ Associate Professor, Department Of Dental Hygiene, College Of Medical Science, Konyang University, \\ Republic Of Korea \\ ${ }^{4}$ Assistant Professor, Department Of Dental Hygiene, Ulsan College, Republic Of Korea \\ ${ }^{5}$ Professor, Department Of Molecular Biology, Dong-Eui University, Republic Of Korea \\ ${ }^{6}$ Associate Professor, Department Of Dental Hygiene, Masan University, Republic Of Korea
}

\begin{abstract}
This study was to investigate the variables related with anxiety and the impact of anxiety on temporomandibular joint disorder by examining 584 high school students in 4 high schools located in Gyeongsangnam-do. Data were analyzed with IBM SPSS Statistics. v. 19.0 and, considered statistically significant as a p-value of $<0.05$. According to the result, those subjects with anxiety showed higher rate of temporomandibular joint disorder when the grade was higher, the daily average time of listening to music and playing games was longer. This result indicated that anxiety has direct/indirect impact on temporomandibular joint disorder and that it is necessary to develop a way for students to control their anxiety by themselves and include the temporomandibular joint disorder related education program in the oral health education program.
\end{abstract}

Keywords: Anxiety, High school students, Temporomandibular joint disorder

\section{Introduction}

According to the information of National Youth Policy Institute titled "Research on current status of mental health of Korean children and adolescents of 2011", the score of negative factors such as anxiety and depression goes higher as they advance into a higher grade caused by school violence and academic stress. $32.3 \%$ of students answered that they had thought of "occasional wish for committing suicide" for the past year $^{1}$. Equally, the data of Korean Bang Junghwan Foundation ${ }^{2}$ shows that only $53.9 \%$ of our country's youth answered they were "content in life" and this result turns out to be the lowest score among 26 OECD countries. The adolescent period is supposed to be designed for preparing the future of one's own and learning the role as a social member ${ }^{3}$, however, the youth is constantly exposed to an environment of psychological tension and mental conflicts due to many types of stress including study duties.

As for preceding studies of stress, Tache and Selye ${ }^{4}$ asserted that the noxious stimulation caused by stress gives rise to changes in physical and physiological function. Fainman ${ }^{5}$ insisted that $1 / 6$ of people experience temporary depressive disorders during their lifetime, while $1 / 4$ goes through anxiety disorders. 1/24 experiences both types of disorders. According to Song and $\mathrm{Ha}^{6}$, the anxiety gives negative influences on social interaction and interpersonal relationship. As for the preceding studies relevant to physical changes caused by stress, Chae ${ }^{7}$ affirms that sedentary workers suffer from hypertonus of head and neck muscles by the anterior head positioning.

Temporomandibular joint disorders (TMD) are also called temporomandibular joint dysfunction and it is a term encompassing many clinical problems in the area of masticatory muscle and temporomandibular joint ${ }^{8}$. Pullinger and Seligma ${ }^{9}$ reported that the incidence rate of TMD of youth increased in their teens, while according to Katzberg et al. ${ }^{10}$ reported that the incidence rate of joint noises raised in their late teens. On the other hand, Lundh and Westesson ${ }^{11}$ insist that about $25 \%$ of the whole population shows symptoms related to TMD. Hence, considering that the incidence rate of TMD happens in younger age group day by day ${ }^{12}$, this study aims to verify the influences anxiety of adolescents on symptoms of TMD and provide materials for counseling program relevant to oral health of youth.

\subsection{Research Subject}

\section{Materials and Methods}

The data collection was carried out from September 1 to 30 of 2014 based on convenience sampling, oriented to 600 female and male students of four high schools located in the Gyeongsangnam-do Province. After the research subjects were instructed regarding the purpose, intent and content of research, the self-administered 
questionnaire survey was conducted to students who agreed on research participation. Among them, 16 students with undependable answers were excluded for the final research subjects and 584 students were selected in the final list.

\subsection{Methods}

The questionnaire questions used for this study were basically based on the materials of Reynold ${ }^{13}$ and Zarb $^{14}$, and modified and complemented by me in quality of researcher in accordance with the purpose of this study. The questionnaire questions were composed of 52 questions in total: 5 general questions, 10 questions about symptoms related to TMD and 37 anxiety-related questions. Among the questions, TMD symptoms counted on 5-point Likert scale. The answer of "strongly disagree" marked 1 point, and "strongly agree" marked 5 points to each question, this way, a higher score means a higher probability of incidence rate of TMD symptoms. As for anxiety-related questions, students answered by "Yes" or "No". Regarding anxiety symptoms, the total score of 37 questions were added all together for finding the median value. When the score was over the median value, it was categorized as "Yes" case of anxiety symptom, while the score was under the media value, it was considered "No" case of the symptom. Thus, a higher score refers to a higher level of anxiety symptom. The results showed that reliability of Cronbach's $\alpha$ of TMD was .903 while that of anxiety was .849 .

\subsection{Analysis of Data}

The collected data was analyzed by IBM-SPSS 19.0 Program and the significance level was set at 0.05 for deciding statistical significance. The general characteristics of research participants proceeded with frequency analysis and the TMD symptoms by general characteristics were analyzed based on t-test and oneway ANOVA and Scheffe's Scheffé post hoc tests were also conducted. The correlation among influential factors of anxiety and TMD was analyzed and multiple regression analysis was carried out to analyze the influential factors of TMD.

\subsection{General Characteristics}

\section{Results}

The general characteristics of research subjects are shown in Table 1 . As for gender, $33.7 \%$ was male and $66.3 \%$ was female. $37.3 \%$ of students were in the second year. School record was "average" up to $35.6 \%$ $86.5 \%$ was with the mean music appreciation time less than 2 hours a day, while $88.0 \%$ was with the mean game-playing time less than two hours per day. As for anxiety, No was $57.7 \%$ while Yes was $42.3 \%$.

Table 1: General characteristics of study subject

\begin{tabular}{|l|l|l|l|}
\hline \multicolumn{1}{|c|}{ Characteristics } & & $\mathrm{N}$ & \multicolumn{1}{c|}{$\%$} \\
\hline \multirow{4}{*}{ Gender } & Male & 197 & 33.7 \\
\cline { 2 - 4 } & Female & 387 & 66.3 \\
\hline \multirow{5}{*}{ Grade } & 1 & 202 & 34.6 \\
\cline { 2 - 4 } & 2 & 218 & 37.3 \\
\cline { 2 - 4 } & 3 & 164 & 28.1 \\
\hline \multirow{5}{*}{ GPA } & Good & 170 & 29.1 \\
\cline { 2 - 4 } & Fair & 208 & 35.6 \\
\cline { 2 - 4 } & Poor & 206 & 35.3 \\
\hline \multirow{5}{*}{ Daily average time of listening to music } & $>2$ hours & 505 & 86.5 \\
\cline { 2 - 4 } & $2 \sim 3$ hours & 46 & 7.9 \\
\cline { 2 - 4 } & $\leq 3$ hours & 33 & 5.7 \\
\hline \multirow{5}{*}{ Daily average time playing games } & $>2$ hours & 514 & 88.0 \\
\cline { 2 - 4 } & $2 \sim 3$ hours & 55 & 9.4 \\
\cline { 2 - 4 } & $\leq 3$ hours & 15 & 2.6 \\
\hline \multirow{2}{*}{ Anxiety } & No & 337 & 57.7 \\
\hline & Yes & 247 & 42.3 \\
\hline & & 584 & 100.0 \\
\hline
\end{tabular}

\subsection{TMD Symptoms by General Characteristics of Research Subjects}

Table 2 shows TMD symptoms by the general characteristics of research subjects. There was statistical significance in terms of gender $(p<0.01)$, school year $(p<0.05)$, the mean music appreciation time a day $(p<$ $0.001)$, the mean game-playing time a day $(p<0.001)$ and anxiety $(\mathrm{p}<0.001)$. Female students showed higher TMD symptoms by showing 2.07 than male students who registered 1.97 . The highest score was shown in the 
third-year students by marking 2.12. As for mean music appreciation time and game-playing time a day, the highest score was shown at 2.29 and 2.43 respectively in the category of more than three hours. As for anxiety, Yes case showed 2.22 while No case showed 1.90, therefore, higher incidence rate of TMD symptoms was shown in students with anxiety.

Table 2: Temporomandibular disorders symptom by the general characteristics

\begin{tabular}{|l|c|c|c|c|}
\hline \multicolumn{1}{|c|}{ Characteristics } & & Mean $\pm \mathrm{SD}$ & $\mathrm{T} / \mathrm{F}$ & $\mathrm{p}$ \\
\hline Gender & Male & $1.97 \pm 0.42$ & -2.840 & $0.005^{* *}$ \\
\hline & Female & $2.07 \pm 0.46$ & & \\
\hline Grade & 1 & $1.98 \pm 0.45 \mathrm{a}$ & 4.196 & $0.016^{*}$ \\
\hline & 2 & $2.03 \pm 0.44 \mathrm{ab}$ & & \\
\hline GPA & 3 & $2.12 \pm 0.44 \mathrm{~b}$ & & \\
\hline & Good & $2.00 \pm 0.46$ & 1.314 & 0.270 \\
\hline & Fair & $2.04 \pm 0.45$ & & \\
\hline Daily average time of listening to music & Poor & $2.07 \pm 0.43$ & & \\
\hline & $>2$ hours & $2.01 \pm 0.49 \mathrm{a}$ & 7.163 & $<0.001 * * *$ \\
\hline & $2 \sim 3$ hours & $2.12 \pm 0.41 \mathrm{ab}$ & & \\
\hline Daily average time playing games & $\leq 3$ hours & $2.29 \pm 0.57 \mathrm{~b}$ & & \\
\hline & $<2$ hours & $2.01 \pm 0.44 \mathrm{a}$ & 10.009 & $<0.001 * * *$ \\
\hline & $2 \sim 3$ hours & $2.18 \pm 0.43 \mathrm{ab}$ & & \\
\hline Anxiety & $\leq 3$ hours & $2.43 \pm 0.41 \mathrm{~b}$ & & \\
\hline & No & $1.90 \pm 0.41$ & -9.045 & $<0.001 * * *$ \\
\hline & Yes & $2.22 \pm 0.43$ & & \\
\hline & & $2.04 \pm 0.44$ & & \\
\hline
\end{tabular}

\subsection{Factors Influencing TMD Symptoms}

Table 3 demonstrates the results of multiple regression analysis conducted to check the factors influencing TMD symptoms, after defining the items with statistical significance as independent variables and TMD symptoms as dependent variables. The factors which influence TMD symptoms turned out to be school year, the mean daily game-playing time and anxiety. In other words, the probability of incidence rate of TMD symptoms increases if students are in a higher school year, have longer mean daily game-playing time and with anxiety.

Table 3: Influence to temporomandibular disorders

\begin{tabular}{|c|c|c|c|c|c|}
\hline Characteristics & & SE & $\beta$ & $p$-value & VIF \\
\hline \multirow[t]{2}{*}{ Gender } & Male & - & & & \\
\hline & Female & .036 & .074 & .058 & 1.045 \\
\hline \multirow[t]{3}{*}{ Grade } & 1 & - & & & \\
\hline & 2 & .040 & .064 & .141 & 1.327 \\
\hline & 3 & .044 & .143 & $<.001 * * *$ & 1.380 \\
\hline \multirow[t]{3}{*}{ GPA } & Good & - & & & \\
\hline & Fair & .043 & .067 & .145 & 1.470 \\
\hline & Poor & .043 & .012 & .796 & 1.483 \\
\hline \multirow[t]{3}{*}{ Daily average time of listening to music } & $>2$ hours & - & & & \\
\hline & $2 \sim 3$ hours & .064 & .009 & .811 & 1.055 \\
\hline & $\leq 3$ hours & .078 & .073 & .069 & 1.131 \\
\hline \multirow[t]{3}{*}{ Daily average time playing games } & $<2$ hours & - & & & \\
\hline & $2 \sim 3$ hours & .059 & .089 & $.023^{*}$ & 1.060 \\
\hline & $\leq 3$ hours & .113 & .124 & $.002 * *$ & 1.126 \\
\hline \multirow[t]{2}{*}{ Anxiety } & No & - & & & \\
\hline & Yes & .035 & .330 & $<.001 * * *$ & 1.078 \\
\hline $\mathrm{F}=12.471, p<0.001$, adjusted $R^{2}=$ & 64. Durbin & atson & 815. & & \\
\hline
\end{tabular}




\section{Discussion}

This study intended to verify the correlation between anxiety of adolescents and their TMD symptoms, based on a wide range of preceding studies relevant to anxiety and stress of youth ${ }^{15-18}$.

Among 584 research subjects, the results showed that 247 students $(42.3 \%)$ were suffering from anxiety, while 337 students $(57.7 \%)$ were without the symptom. According to relevant materials ${ }^{19}, 69.6 \%$ of youth aged from 15 to 24 answered that they were under stress in "overall aspect of daily life" in 2010 . This information actually showed increase by $13.1 \%$ as compared with the data of 2008 which was up to $56.5 \%$ regarding the same topic. Moreover, 7 out of 10 aged from 15 to 19 turned out to suffer from stress in "school life" and "overall aspect of daily life". This implies the seriousness of the problem. As for TMD symptoms by the general characteristics of research subjects, female students showed a higher level than male students, by registering 2.07 and 1.97 respectively. Hong ${ }^{20}$ supports the research results by saying that female showed a higher level of TMD symptoms and bad oral habits than male, in her research regarding TMD symptoms and bad oral habits relevant to stress. In the preceding studies related to TMD symptoms of youth, female adolescents are excluded as research subjects and only male adolescents were selected ${ }^{21,22}$. For this reason, this fact must be considered for follow-up studies at the moment of selecting research subjects. While the students' school year was higher, the score of TMD score showed higher accordingly.

According to the research of Chung and $\mathrm{Hong}^{22}$, in the research oriented to the first-year and the second-year male student of high school, the second-year students showed a higher level in all 5 stress domains than the first-year students. Also, there was a significant difference between students with TMD experience and those without the experience. It is estimated that students suffer from higher anxiety caused by the fear for university entrance examination and their uncertain future while they advance into a higher grade. As for the mean daily music appreciation time and game-playing time, the highest level was shown in the range over 3 hours. Goh and $\mathrm{Kim}^{23}$ insisted that internet use frequency of the youth gave bad influences on depression, attention-concentration and relationship with teachers and peers, while Roh ${ }^{24}$ argued that Internet addiction and ADHD symptoms worked as mediating effects. Backed up by the surprising progress of IT industry, diverse contents industries based on Internet are penetrating in our daily lives. In particular, the youth sensitive to new cultural industry will be the main protagonist of using Internet-based culture such as music and game. Today, in which the convenience and negative effects coexist, this study proposes the necessity of follow-up studies relevant to this subject. Research participants with anxiety showed statistical significance by showing the score of 2.22 as compared with those without anxiety registering the score of $1.90(p<0.001)$. The research of Chung and Hong ${ }^{22}$ showed a significant result of correlation between stress and bad oral habits by -0.27 . In the same way, Lee and $\mathrm{Choi}^{21}$ confirmed that school stress gave influences with significant difference on joint noises, pain while masticating, pain while not masticating and headache $(p<0.01)$. The research results are supported by these preceding studies. As shown in the preceding studies and this study, anxiety and stress affects TMD, but in inverse case, people with TMD also suffer from stress caused by TMD as compared with people without TMD symptoms. This fact implies the necessity of follow-up cohort study, and it is expected to have various research results based on these variables. According to the result of multiple regression analysis regarding the factors influencing TMD symptoms, it was possible to confirm how independent variables influence dependent variables by proving that the high score was with a higher school year, longer daily game-playing time and those with anxiety. As for limitations of this research, it was difficult to generalize the research subjects as a whole because the result was obtained by only a cross-sectional research based on convenience sampling oriented to partial high school students. Therefore, it is not sufficient to interpret the order of relation of the research results. This study proposes the necessity of active follow-up comparative studies regarding diverse factors influencing TMD, comparison of male high school students with female high school students, as well as students of specialized schools.

\section{Acknowledgements}

This research was supported by Choonhae College of Health Sciences in 2015.

\section{References}

[1]. I.J. Choi, and S.H. Mo, Study on mental health improvement policy for children and adolescents II (Seoul: National Youth Policy Institute, 2012), 1-27.

[2]. K.S. Lee, The 2010 Korean children and youth panel survey III project report (Seoul: National Youth Policy Institute, 2013), 3-30.

[3]. N.J. Kim, and Y.S. Lim, The verification of intervening effect of youth activity on the relationship between stress and life satisfaction of adolescents, Korean Journal of Youth Studies, 2012, 19(8): 219-240

[4]. J. Tache, and H. Selye, On stress and coping mechanisms, Issue in Mental Health Nursing, 1985, 7: 3-24.

[5]. D. Fainman, Examining the relationship between anxiety disorders and depression, Anxiety Disorders and Depression, 2004, 22: 568-571.

[6]. E.Y. Song, and E.H. Ha, The effects of adolescent's traumatic experience, perfectionism and negative automatic thoughts on social anxiety, Cognitive-Behavioral Therapies, 2008, 8(1): 41-56. 
[7]. Y.W. Chae, The measurement of forward head posture and pressure pain threshold in neck muscle, The Journal of Korean Physical Therapy, 2002, 14: 117-124.

[8]. P.B. Luciana, O.S. Tatiana, and A.A. Thays, Association between headache and temporomandibular joint disorders in children and adolescents, Journal of Oral Science, 2013, 55: 39-43.

[9]. A.G. Pullinger, and D.A. Seligma, TMJ ostedarthrosis: a differentiation of diagnostic subgroups by symptom history and demographics, Journal of Craniomandibular Disorders: Facial Oral Pain, 1987, 1: 251-256.

[10]. R. Katzberg, R. Tallent, K. Hayakawa, T. Miller, M. Goske, and B. Wood, Internal derangements of the temporomandibular joint: findings in the pediatric age group, Radiology, 1985, 154:125-127.

[11]. H. Lundh, and P.L. Westesson, Clinical signs of temporomandibular joint internal derangement in adult, Oral Surgery, Oral Medicine, Oral Pathology, Oral Radiology, 1991, 72: 634-641.

[12]. E.J. Park, and Y.J. Yoon, Relationship between the prevalence of temporomandibular joint disorders in some male high school students and computer utilization, Journal of Korean Society of Dental Hygiene, 2013, 13: 651-657.

[13]. C.R. Reynolds, and B.O. Richmond, Factor structure and construct validity of "what I think and feel": the revised children's manifest anxiety scale, Journal of Personality Assessment, 1979, 43: 281-283.

[14]. G.A. Zarb, and G.E. Carlsson, Temporomandibular disorders: osteoarthritis, Journal of Orofacial Pain, 1999, 13: 295-306.

[15]. N.J. Kim, and Y.S. Lim, The verification of intervening effect of youth activity on the relationship between stress and life satisfaction of adolescents, Korean Youth Research Association, 2012, 19: 219-240.

[16]. S.H. Jang, and K.D. Joo, Effects of Depression Scale, Interaction Anxiety and School Adjustment on Cellular Phone Addiction of Teenagers, Korean Journal of Contents, 2010, 10: 285-293.

[17]. M.H. Kim, Comparison of the effect of Maum meditation program on the depression, anxiety and self-esteem of the children and the juveniles, Korean Journal of Contents, 2012, 12: 338-348.

[18]. S.J. Kwon, and Y.J. Choi, Impact of the type of dental treatment on the dental fear of adolescents in south Gyeongsang Province, Korean Journal of Contents, 2010, 10: 277-285.

[19]. Minister of Gender Equality \& Family, Medical world news (Statistics Korea, 2013), 3-40.

[20]. M.H. Hong, Relationship of stress, oral habits and TMJ symptoms in 20-30 ages adults, Journal of Korean Society of Dental Hygiene, 2014, 14: 739-746.

[21]. J.H. Lee, and J.M. Choi, A study on the temporomandibular joint disorder and school life stress of high school student by department, Journal of Dental Hygiene Science, 2007, 7: 179-185.

[22]. Y.Y. Chung, and J.T. Hong, A study of the relation of stress to oral parafunctional habits of male high school students, Journal of Dental Hygiene Science, 2013, 13: 471-479.

[23]. E.H. Ko, and E.J. Kim, The effects of depression, inattention, internet use and teacher-student/peer relationships on cyber delinquency in adolescents: testing the moderated mediation effect, Korean Youth Research Association, 2015, 22: 1-26.

[24]. S.J. Roh, D.H. Lee, and Y.J. Song, Effects of attention-deficit hyperactivity disorder (ADHD), depression, and anxiety on internet addiction among vocational high school students, Asia Education Research, 2011, 12: 25-53. 